\title{
Effects of coenzyme Q10 supplementation on activities of selected antioxidative enzymes and lipid peroxidation in hypertensive patients treated with indapamide. A pilot study
}

Kornelia Kędziora-Kornatowskaํ, Jolanta Czuczejko², Jadwiga Motyl1, Karolina Szewczyk-Golec², Mariusz Kozakiewicz², Hanna Pawluk², Józef Kędziora², Robert Błaszczak³, Maciej Banach4, Jacek Rysz ${ }^{3}$

1Department and Clinic of Geriatrics, Nicolaus Copernicus University Collegium Medicum, Bydgoszcz, Poland

2Department of Biochemistry, Nicolaus Copernicus University Collegium Medicum, Bydgoszcz, Poland

3Department of Nephrology, Hypertension and Family Medicine, Medical University of Lodz, Poland

${ }^{4}$ Department of Hypertension, Medical University of Lodz, Poland

Submitted: 13 April 2010

Accepted: 19 July 2010

Arch Med Sci 2010; 6, 4: 513-518

DOI: 10.5114/aoms.2010.14461

Copyright $\Subset 2010$ Termedia \& Banach

\begin{abstract}
Introduction: An increase in oxidative stress is strongly documented in hypertensive patients. In blood vessels, oxidative stress increases the production of superoxide anion $\left(\mathrm{O}_{2}^{--}\right)$that reacts with nitric oxide (NO) and impairs the ability of endothelium to relax. Many reports indicate a beneficial effect of coenzyme Q10 (CoQ) in hypertension. Coenzyme Q10 therapy may lower $\mathrm{O}_{2}{ }^{\cdot-}$ and thus decrease the complications associated with hypertension. The aim of our study was to evaluate the effects of CoQ supplementation on antioxidative enzyme activities and lipid peroxidation in elderly hypertensive patients.

Material and methods: We determined the activities of superoxide dismutase (SOD-1) and glutathione peroxidase (GSH-Px) and the concentration of malondialdehyde (MDA) in erythrocytes of 27 elderly (mean age $72.5 \pm 6.1$ year) hypertensive patients treated with indapamide at baseline and after 12 weeks of CoQ supplementation ( $60 \mathrm{mg}$ twice a day) in comparison with 30 healthy elderly volunteers (mean age $76.8 \pm 8.5$ year).

Results: Decrease of SOD-1 $(p<0.001)$ and insignificant reduction of GSH-Px activities and increase of MDA $(p<0.001)$ level were observed in hypertensive patients in comparison to healthy volunteers before supplementation. Coenzyme Q10 administration resulted in a significant increase only in SOD-1 activity $(p<0.001)$.

Conclusions: The present study indicates that $\mathrm{CoQ}$ improves the most important component of the antioxidant defence system - SOD-1, which is responsible for $\mathrm{O}_{2}{ }^{\cdot-}$ scavenging. Coenzyme Q10 may be used as an additional therapeutic agent for prophylaxis and treatment of hypertension in elderly patients.
\end{abstract}

Key words: aging, glutathione peroxidase, hypertension, oxidative stress, superoxide dismutase.
Corresponding author: Dr Jolanta Czuczejko Department of Biochemistry Nicolaus Copernicus University Collegium Medicum 24 Karłowicza Str. 85-092 Bydgoszcz, Poland Phone: +48 525853755 Fax: +48 525853771 E-mail: joczu@wp.pl 


\section{Introduction}

In 1972 Igarashi et al. [1] reported that coenzyme Q10 (CoQ) reduced elevated blood pressure in rats treated with desoxycorticosterone and saline. Subsequently, CoQ supplementation has been demonstrated to have a hypotensive effect [2-4]. A possible explanation of these findings may be the antioxidative properties of CoQ. The pathogenesis of primary hypertension is multifactorial. It has been accepted that oxidative stress and augmented production of reactive oxygen species (ROS), mainly superoxide anion $\left(\mathrm{O}_{2}{ }^{\cdot-}\right)$, may have a key role [5-7]. Overproduction of $\mathrm{O}_{2}{ }^{--}$results from increased tissue renin-angiotensin system (RAS) activation [6-8]. The RAS is responsible for angiotensin II (AngII) synthesis, and additionally aldosterone potentiates the actions of this peptide [9]. Angiotensin II enhances the generation of $\mathrm{O}_{2}{ }^{--}$via an increase of nicotinamide adenine dinucleotide (phosphate) reduced oxidase ( $\mathrm{NAD}(\mathrm{P}) \mathrm{H}$-oxidase) activity in endothelium, vascular smooth muscle and leukocytes $[5,8,10]$. In a reaction with $\mathrm{O}_{2}{ }^{\cdot-}$, vasodilatory nitric oxide (NO) is inactivated by conversion to peroxynitrite $[11,12]$. This powerful oxidant reacts with polyunsaturated fatty acids and in this way initiates lipid peroxidation [11]. As a result, vessel wall degradation and endothelium damage may occur [12]. Moreover, ROS increase the synthesis of several vasoconstrictors, such as F2 $\alpha$-isoprostanes, endothelin and thromboxane $\mathrm{A}_{2}$, and decrease synthesis of vasodilatory prostacyclin [5]. Experimental evidence indicates that reduction in NO availability, endothelium cell damage and disturbances in synthesis of several tissue hormones via impaired endothelium-dependent vasodilation may lead to primary hypertension development $[5,8,13]$.

Coenzyme Q10 exerts some impact on the generation and half-life of $\mathrm{O}_{2}{ }^{\cdot-}$. There are two potential ways in which $\mathrm{CoQ}$ might suppress $\mathrm{O}_{2}{ }^{\cdot-}$ production. One possibility is that $\mathrm{CoQ}$ decreases cytoplasmic NADH concentration by enhancing electron shuttle mechanisms that transfer electrons and $\mathrm{H}^{+}$from cytoplasmic NADH to the mitochondrial respiratory chain. Another possibility is that CoQ collects electrons in all cells' plasma membranes which otherwise could be used for generation of $\mathrm{O}_{2} \cdot{ }^{--}$[14]. Decreased levels of reducing equivalents prevent $\mathrm{NADH}$-oxidase from generating $\mathrm{O}_{2}^{\cdot-}$ in endothelium and vascular smooth muscle cells.

Organisms have developed several enzymatic and non-enzymatic antioxidant mechanisms to scavenge ROS. The major antioxidative enzymes include superoxide dismutase (SOD-1), which catalyzes the dismutation of $\mathrm{O}_{2}{ }^{\cdot-}$ to hydrogen peroxide $\left(\mathrm{H}_{2} \mathrm{O}_{2}\right)$, and glutathione peroxidase (GSH-Px), which catalyzes the dismutation of $\mathrm{H}_{2} \mathrm{O}_{2}$
[15]. One of the intriguing ideas is that CoQ may exert an influence on activities of antioxidative enzymes and in this way reduce the level of ROS.

Therefore the aim of the study was to investigate the effects of CoQ supplementation on SOD-1 and GSH-Px activities in elderly hypertensive patients. In addition a lipid peroxidation marker, malondialdehyde (MDA) concentration, was determined.

\section{Material and methods}

\section{Participants}

Twenty-seven elderly (mean age $72.5 \pm 6.1$ year) hypertensive patients treated with indapamide at baseline and after 12 weeks of CoQ supplementation (60 mg twice a day) in comparison with 30 healthy elderly volunteers (mean age $76.8 \pm 8.5$ year) were included in the study. The patients were evaluated by a standard physical examination and routine clinical laboratory tests. Persons addicted to alcohol and/or tobacco, and patients with diabetes mellitus, ischaemic heart disease, a history of stroke, renal failure or other conditions of known free radical aetiology were excluded from the study.

All participants provided written consent to participate in the experiment, which was approved by the local ethics committee of Collegium Medicum in Bydgoszcz, Poland.

\section{Experimental protocols}

Each patient was treated with a pharmaceutical preparation of $60 \mathrm{mg}$ of CoQ twice a day for 12 weeks. Blood samples were collected after overnight fasting from the cubital vein into polypropylene heparinized tubes $(6 \mathrm{ml})$ a day before supplementation, and after 12 weeks of CoQ treatment.

All samples were centrifuged (2500 g for $10 \mathrm{~min}$ ). After plasma removal, the haemolysate was prepared by threefold freezing and thawing the washed erythrocytes, suspended in bi-distilled water.

\section{Biochemical analysis}

Erythrocytic MDA, SOD-1, and GSH-Px were assayed according to the methods of Placer et al. [16], Misra and Fridovich [17], and Paglia and Valentine [18], respectively. The MDA level was expressed as the concentration of thiobarbituric acid reactive substances, read at $532 \mathrm{~nm}$. The SOD-1 activity was determined at $37^{\circ} \mathrm{C}$ by recording the increase in absorbance at $480 \mathrm{~nm}$ following the auto-oxidation of adrenaline, inhibited by SOD-1. One unit $(U)$ of this activity is defined as the amount of enzyme inhibiting the adrenaline autooxidation by $50 \%$. The GSH-Px activity was 
determined at $25^{\circ} \mathrm{C}$ by recording the decrease in absorbance at $340 \mathrm{~nm}$ following the oxidation of $\mathrm{NADPH}$ in the presence of tert-butyl hydroperoxide as a substrate. One unit (U) of this activity is defined as the amount of the enzyme oxidizing $1 \mu \mathrm{mol} \mathrm{NADPH} / \mathrm{min}$. The haemoglobin concentration in the haemolysate was estimated after conversion into cyanmethaemoglobin form using a commercial reagent (Biomed, Poland) read at $540 \mathrm{~nm}$.

\section{Statistical analysis}

All the results were expressed as mean \pm SEM. One-way analysis of variance followed by the Tukey post hoc test was performed to determine the statistical significance of differences. The level of significance was set at $p<0.05$.

\section{Results}

The clinical characteristics of the examined groups are presented in Table I. The parameters of oxidative stress in erythrocytes of elderly hypertensive subjects differed from the results obtained for healthy elderly volunteers: MDA level $(0.288 \pm 0.039 \mu \mathrm{mol} / \mathrm{g} \mathrm{Hb}$ and $0.223 \pm 0.038 \mu \mathrm{mol} / \mathrm{g} \mathrm{Hb}$, respectively) (Figure 1) was significantly higher $(p<0.001)$, activity of SOD-1 (2431 $\pm 266 \mathrm{U} / \mathrm{g} \mathrm{Hb}$ and $2916 \pm 352 \mathrm{U} / \mathrm{g} \mathrm{Hb}$, respectively) (Figure 2) was significantly lower $(p<0.001)$ and activity of GSH-Px $(14.7 \pm 3.2 \mathrm{U} / \mathrm{g} \mathrm{Hb}$ and $16.3 \pm 1.6 \mathrm{U} / \mathrm{g} \mathrm{Hb}$, respectively) (Figure 3) was insignificantly lower.

Twelve weeks of CoQ supplementation caused a significant decrease $(p<0.001)$ in the erythrocytic MDA level (0.255 $\pm 0.026 \mu \mathrm{mol} / \mathrm{g} \mathrm{Hb})$ (Figure 1) and

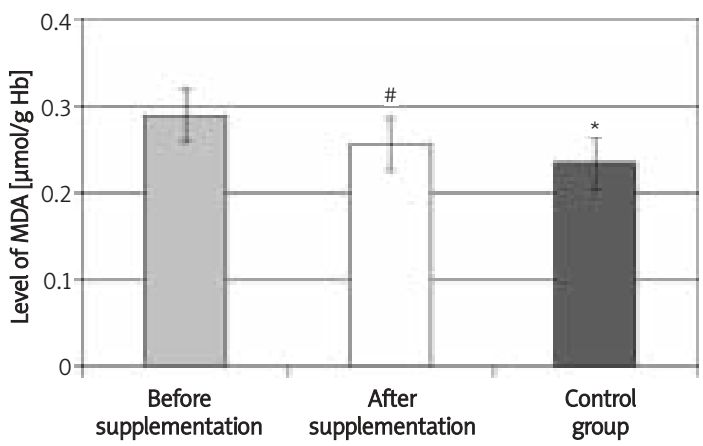

Figure 1. Effect of coenzyme Q10 (CoQ) supplementation on the concentration of malondialdehyde (MDA) in erythrocytes of elderly hypertensive patients in comparison with healthy elderly volunteers. All parameters were measured at baseline in both groups and after 12 weeks of $\mathrm{CoQ}$ administration in the hypertensive group. Each value is mean \pm SEM

${ }^{*} p<0.001$ hypertensive patients before supplementation vs. healthy elderly subjects, ${ }^{*} p<0.001$ hypertensive patients before supplementation vs. after supplementation
Table I. Clinical characteristics of study subjects

\begin{tabular}{|lcc|}
\hline Parameters & $\begin{array}{c}\text { Healthy } \\
\text { elderly } \\
\text { volunteers }\end{array}$ & $\begin{array}{c}\text { Elderly } \\
\text { hypertensive } \\
\text { group }\end{array}$ \\
\hline Number of subjects & 30 & 27 \\
\hline Age [years] & $76.8 \pm 8.5$ & $72.5 \pm 6.1$ \\
\hline Sex (number of subjects) M/F & $7 / 23$ & $7 / 20$ \\
\hline BMl [kg/m ${ }^{2}$ ] & $24.8 \pm 4.6$ & $30.9 \pm 3.4$ \\
\hline $\begin{array}{l}\text { Systolic blood pressure } \\
\text { [mmHg] }\end{array}$ & $120.6 \pm 4.8$ & $152.8 \pm 9.3$ \\
\hline $\begin{array}{l}\text { Diastolic blood pressure } \\
\text { [mmHg] }\end{array}$ & $80.0 \pm 5.0$ & $82.5 \pm 6.9$ \\
\hline $\begin{array}{l}\text { Plasma total cholesterol } \\
\text { [mg/dl] }\end{array}$ & $178.9 \pm 15.8$ & $195 \pm 28$ \\
\hline Plasma triglyceride [mg/dl] & $135.4 \pm 18.4$ & $154.5 \pm 11.2$ \\
\hline Plasma glucose [mg/dl] & $93.28 \pm 16.26$ & $82.9 \pm 8.7$ \\
\hline Serum creatinine [mg/dl] & $1.0 \pm 0.3$ & $0.9 \pm 0.13$ \\
\hline
\end{tabular}

$B M I$ - body mass index, $M$ - male, $F$-female

significant increase $(p<0.001)$ in erythrocytic SOD-1 activity (2677 $\pm 321 \mathrm{U} / \mathrm{g} \mathrm{Hb}$ ) (Figure 2) in elderly hypertensive patients. Coenzyme Q supplementation did not influence the erythrocytic activity of GSH-Px (16.1 $\pm 2.3 \mathrm{U} / \mathrm{g} \mathrm{Hb})$ (Figure 3) in elderly hypertensive patients.

\section{Discussion}

Many authors have observed that augmented ROS production exceeds the capacity of the antioxidative system in the elderly $[19,20]$. Enhanced

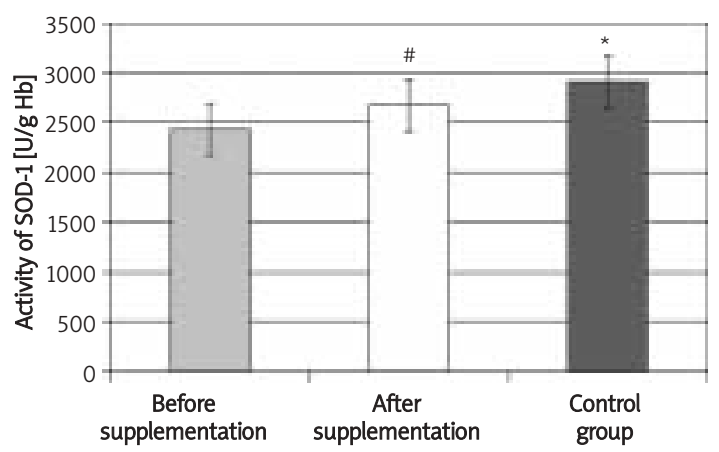

Figure 2. Effect of coenzyme Q10 (CoQ) supplementation on the activity of superoxide dismutase (SOD-1) in erythrocytes of elderly hypertensive patients in comparison with healthy elderly volunteers. All parameters were measured at baseline in both groups and after 12 weeks of CoQ administration in the hypertensive group. Each value is mean \pm SEM

${ }^{*} p<0.001$ hypertensive patients before supplementation vs. healthy elderly subjects, ${ }^{*} p<0.001$ hypertensive patients before supplementation vs. after supplementation 


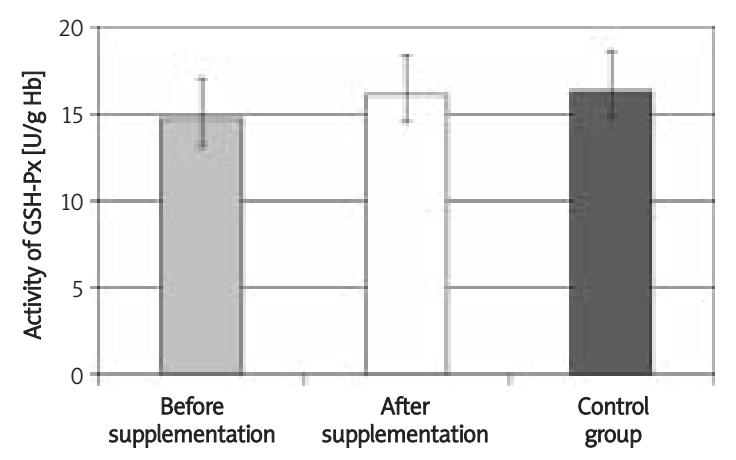

Figure 3. Effect of coenzyme Q10 (CoQ) supplementation on the activity of glutathione peroxidase (GSH-Px) in erythrocytes of elderly hypertensive patients in comparison with healthy elderly volunteers. All parameters were measured at baseline in both groups and after 12 weeks of CoQ administration in the hypertensive group. Each value is mean $\pm \mathrm{SEM}$

levels of ROS by-products, such as MDA, carbonyl groups, advanced end products of glycation and damaged 8-oxo-2'-deoxyguanosine, were found in elderly people [21]. Hypertension is an agedependent disorder and oxidative stress may be involved in the development of this disease. In our study erythrocyte MDA level was significantly higher in the essential hypertensive patients as compared to the control group before treatment with $\mathrm{CoQ}$. Significantly higher MDA concentrations in erythrocytes and plasma of hypertensive patients have been observed in many studies [22-26]. Uddin et al. [27] noticed a 2.6-fold higher level of MDA in the aorta of hypertensive mice than that of normotensive ones. These findings suggest that increased lipid peroxidation may be associated with elevated blood pressure. Additionally, increased concentration of MDA may contribute to the development of hypertension complications [22, 28].

Decreased activities of the antioxidative enzymes SOD-1 and GSH-Px in hypertensive patients before treatment were found in the present study but only SOD-1 activity was diminished significantly. In our previous study a significant age effect on decreasing activity of GSH-Px was found [29]. As opposed to the present results, Se-dependent GSH-Px activity was reported to be unchanged or increased in several publications [27, 30, 31]. Uddin et al. [27] observed unchanged GSH-Px activity in hypertensive mouse aorta. Patients with essential hypertension exhibited increased GSH-Px activity compared to normotensive persons in the study of Simic et al. [31].

Lowered SOD-1 activity in erythrocytes of patients with essential hypertension was reported by Baykal et al. [23], Kumar and Das [24] and Donmez et al. [32]. A possible explanation of decreased SOD-1 activity in elderly people could be a $\mathrm{Zn}^{2+}$ ion deficiency, which may be connected with poor diet of elderly people [30]. According to some authors the reason for diminished activity of SOD-1 may be the oxidative modifications of enzymatic proteins. Researchers emphasize that protein damage induced by ROS may be related to increasing age [33, 34].

Kontush et al. [35] reported a significantly lower level of $\mathrm{CoQ}$ in blood of hypertensive patients. The studies by Sohal et al. [36] indicate that supplementation of CoQ elevates the endogenous content of this compound. Generally, the administration of CoQ directly improved the efficiency of antioxidative defence in the present study. A particularly noteworthy result is a significant rise of SOD-1 activity after CoQ supplementation. Three isoforms of SODs exist, but SOD-1 is the major vascular isoform and is important in scavenging of $\mathrm{O}_{2}{ }^{--}$and enhancing availability of endothelial $\mathrm{NO}$ [37]. The reaction between $\mathrm{O}_{2}{ }^{--}$and $\mathrm{NO}$ occurs 6 times faster than the removal of $\mathrm{O}_{2}^{\cdot-}$ by SOD-1. So, increased SOD-1 activity via CoQ supplementation may be very important in the improvement of endothelial function. Tiano et al. [38] reported an improvement in endothelium-dependent vasodilation and an increase in extracellular SOD-1 activity in the CoQ-treated group of patients. Sena et al. [39] reported that CoQ therapy increases Mn-SOD activity in the pancreas of type 2 diabetic rats. The present study showed that also the activity of GSH-Px increased after CoQ supplementation compared to the activity observed in the control group, but this rise was insignificant. Contrary to these results, Sohal et al. [36] found that intake of CoQ had no effect on SOD- 1 and GSH-Px activities.

Moreover, we observed that $\mathrm{CoQ}$ treatment decreased erythrocytic MDA concentration, suggesting that this compound may diminish ROS concentration. Decreased MDA levels in the plasma after administration of $\mathrm{CoQ}$ were also noted by Ankola et al. [40]. In the study by Sena et al. [39] CoQ treatment decreased pancreatic MDA level in diabetic rats.

In conclusion, the results from the present study provide evidence for an increase in MDA level and a decrease in activities of antioxidative enzymes in hypertensive patients before Q10 supplementation and suggest that these changes may be associated with the process of hypertension. The improvement of oxidative stress parameters after CoQ supplementation confirms the antioxidative properties of this compound. As was mentioned above, clinical studies indicate a deficiency of $\mathrm{CoQ}$ concentration in hypertensive patients. Therefore, taking into account both hypotensive and antioxidative properties of CoQ, we suggest the supplementation of elderly hypertensive patients with this compound as an alternative complementary treatment. However, due to the small number of patients, 
further, more comprehensive studies will be needed to confirm the results of our study and support our suggestions.

\section{References}

1. Igarashi T, Tanabe Y, Nakajima Y, Kobayashi M, Tanaka M. Effect of coenzyme Q10 on experimental hypertension in the desoxycorticosterone acetate-saline loaded rats. Nippon Yakurigaku Zasshi 1972; 68: 460-72.

2. Burke BE, Neuenschwander R, Olson RD. Randomised double-blind, placebo-controlled trial of coenzyme $Q$ in isolated systolic hypertension. South Med J 2001; 94: 1112-7.

3. Dhalla NS, Temsah RM, Netticadan T. Role of oxidative stress in cardiovascular diseases. J Hypertens 2000; 18: 655-73.

4. Hodgson JM, Watts GF, Playford DA, Burke V, Croft KD. Coenzyme Q10 improves blood pressure and glycaemic control: a controlled trial in subjects with type 2 diabetes. Eur J Clin Nutr 2002; 56: 1137-42.

5. Prasad K. Oxyradicals as a mechanism of angiotensininduced hypertension. Int J Angiol 2004; 13: 59-66.

6. Miguel-Carrasco JL, Monserrat MT, Mate A, Vázquez CM. Comparative effects of captopril and I-carnitine on blood pressure and antioxidant enzyme gene expression in the heart of spontaneously hypertensive rats. Eur J Pharmacol 2010; 632: 65-72.

7. Hirooka Y, Sagara Y, Kishi T, Sunagawa K. Oxidative stress and central cardiovascular regulation. Pathogenesis of hypertension and therapeutic aspects. Circ J 2010; 74: 827-35.

8. Wolf G. Free radical production and angiotensin. Curr Hypertens Rep 2000; 2: 167-73.

9. Refaat S, El-Ghaffar NA, El-Rahman Negm HA, Yousri T. The role of aldosterone in myocardial dysfunction of Egyptian patients with essential hypertension. Arch Med Sci 2008; 4: 161-6.

10. Johnson P. Antioxidant enzyme expression in health and disease: effects of exercise and hypertension. Comp Biochem Physiol C Toxicol Pharmacol 2002; 133: 493-505.

11. Bartosz G. Peroxynitrite: mediator of the toxicaction of nitric oxide. Acta Biochim Pol 1996; 43: 645-59.

12. Guzik TJ, West NE, Pillai R, Taggart DP, Channon KM. Nitric oxide modulates superoxide release and peroxinitrite formation in human blood vessels. Hypertension 2002; 39: 1088-94.

13. Goch A, Banach M, Mikhailidis DP, Rysz J, Goch JH. Endothelial dysfunction in patients with noncomplicated and complicated hypertension. Clin Exp Hypertens 2009; 31: 20-30.

14. McCarty MF. Coenzyme Q versus hypertension: does CoQ decrease endothelial superoxide generation? Med Hypotheses 1999; 53: 300-4.

15. Fridovich I. The biology of oxygen radicals. Science 1978; 201: 875-80.

16. Placer Z, Cushman L, Johnson B. Estimation of product of lipid peroxidation malondialdehyde in biochemical systems. Anal Biochem 1966; 16: 359-64.

17. Misra HP, Fridovich I. The role of superoxide anion in the auto-oxidation of epinephrine and a simple assay for superoxide dismutase. J Biol Chem 1972; 247: 3170-5.

18. Paglia DE, Valentine WN. Studies on the quantitative and qualitative characterization of erythrocyte glutathione peroxidase. J Lab Clin Med 1967; 70: 158-69.
19. Sohal RS, Weindruch R. Oxidative stress, caloric restriction, and aging. Science 1996; 273: 59-63.

20. Junqueira VB, Barros SB, Chan SS, et al. Aging and oxidative stress. Mol Aspects Med 2004; 25: 5-16.

21. Schöneich C. Reactive oxygen species and biological aging: a mechanistic approach. Exp Gerontol 1999; 34: 19-34.

22. Atamer A, Ilhan N, Kocyigit Y, Toprak G, Ozbay M, Celik Y. The role of asymmetric dimethylarginine (ADMA) and lepton in hypertensive patients. J Int Med Res 2008; 36: 54-62.

23. Baykal Y, Yilmaz MI, Celik T, et al. Effects of antihypertensive agents, alpha receptor blockers, beta blockers and calcium channel blockers on oxidative stress. J Hypertens 2003; 21: 1207-11.

24. Kumar CA, Das UN. Lipid peroxides, anti-oxidants and nitric oxide in patients with pre-eclampsia and essential hypertension. Med Sci Monit 2000; 6: 901-7.

25. Sathiyapira V, Selvaraj N, Nandeesha H, Bobby Z, Agrawal A, Pavithran P. Enhanced glycation of hemoglobin and plasma proteins is associated with increased lipid peroxide levels in non-diabetic hypertensive subjects. Arch Med Res 2007; 38: 822-6.

26. Srinivas K, Bhaskar MV, Aruna Kumari R, Nagaraj K, Reddy KK. Antioxidants, lipid peroxidation and lipoproteins in primary hypertension. Indian Heart J 2000; 52: 285-8.

27. Uddin M, Yang H, Shi M, Polley-Mandal M, Guo Z. Elevation of oxidative stress in the aorta of genetically hypertensive mice. Mech Ageing Dev 2003; 124: 811-7.

28. Stawiarska-Pięta B, Birkner E, Szaflarska-Stojko E, et al. The influence of diet supplementation with methionine on the pathomorphological changes of rabbit organs in experimental atherosclerosis. Arch Med Sci 2008; 4: 371-9.

29. Kędziora-Kornatowska K, Szewczyk-Golec K, Czuczejko J, et al. Effect of melatonin on the oxidative stress in erythrocytes of healthy young and elderly subjects. J Pineal Res 2007; 42: 153-8.

30. Bolzan AD, Bianchi MS, Bianchi NO. Superoxide dismutase, catalase and glutathione peroxidase activities in human blood: influence of sex, age, and cigarette smoking. Clin Biochem 1997; 30: 449-54.

31. Simic DV, Mimic-Oka J, Pljesa-Ercegovac $M$, et al. Byproducts of oxidative protein damage and antioxidant enzyme activities in plasma with different degrees of essential hypertension. J Hum Hypertens 2006; 20: 149-55.

32. Donmez G, Derici U, Erbas D, Arinsoy T. The effects of losartan and enalapril therapies on the levels of nitric oxide, malondialdehyde, and glutathione in patients with essential hypertension. Jpn J Physiol 2002; 52: 435-40.

33. Augustyniak A, Skrzydlewska E. Antioxidative abilities during aging. Postepy Hig Med Dosw 2004; 58: 194-201.

34. Sohal RS. Role of oxidative stress and protein oxidation in the aging process. Free Radic Biol Med 2002; 33: 37-44.

35. Kontush A, Reich A, Baum K, et al. Plasma ubuquinol-10 is decreased in patients with hyperlipidaemia. Atherosclerosis 1997; 129: 119-26.

36. Sohal RS, Kamzalov S, Sumien N, et al. Effect of coenzyme Q10 intake on endogenous coenzyme Q content, mitochondrial electron transport chain, antioxidative defenses, and life span of mice. Free Radic Biol Med 2006; 40: 480-7.

37. Li Y, Huang TT, Carlton EJ, et al. Dilated cardiomyopathy and neonatal lethality in mutant mice lacking manganese superoxide dismutase. Nat Genet 1995; 11: 376-81.

38. Tiano L, Belardinelli R, Carnevali P, Principi F, Seddaiu G, Littarru GP. Effect of coenzyme Q10 administration on 
endothelial function and extracellular superoxide dismutase in patients with ischaemic heart disease: a double-blind, randomized controlled study. Eur Heart J 2007; 28: 2249-55.

39. Sena CM, Nunes E, Gomes A, et al. Supplementation of coenzyme Q10 and alpha-tocopherol lowers glycated hemoglobin level and lipid peroxidation in pancreas of diabetic rats. Nutr Res 2008; 28: 113-21.

40. Ankola DD, Viswanad B, Bhardwaj V, Ramarao P, Rav Kumar MN. Development of potent oral nanoparticulate formulation of coenzyme Q10 for treatment of hypertension: can the simple nutritional supplements be used as first line therapeutic agents for prophylaxis/therapy? Eur J Pharm Biopharm 2007; 67: 361-9. 